\title{
Erythema multiforme after orf virus infection: a report of two cases and literature review
}

\author{
R. H. JOSEPH ${ }^{1,2 *}$, F. A. HADDAD ${ }^{3}$, A. L. MATTHEWS ${ }^{4}$, A. MAROUFI ${ }^{2}$, \\ B. MONROE ${ }^{5}$ AND M. REYNOLDS ${ }^{5}$ \\ ${ }^{1}$ Epidemic Intelligence Service, Centers for Disease Control and Prevention, Atlanta, GA, USA \\ ${ }^{2}$ County of San Diego Health and Human Services Agency, San Diego, CA, USA \\ ${ }^{3}$ Infectious Diseases Section, Sharp Grossmont Hospital, La Mesa, CA, USA \\ ${ }^{4}$ Billings Clinic, Billings, MT, USA \\ ${ }^{5}$ Poxvirus Branch, National Center for Emerging, Zoonotic and Infectious Diseases, Centers for Disease Control \\ and Prevention, Atlanta, GA, USA
}

Received 5 February 2014; Final revision 12 March 2014; Accepted 19 March 2014;

first published online 8 May 2014

\section{SUMMARY}

Orf virus has a worldwide distribution among sheep and goats. The hypersensitivity reaction erythema multiforme (EM) is a known complication of orf infection in humans; however, its occurrence is poorly understood and has not been extensively reviewed. We present two unrelated cases of orf-associated EM, and a review of the literature, highlighting important clinical, epidemiological and immunological aspects of this condition. Orf and its associated complications can occur in rural areas, as well as urban settings, where it is less well-known, through religious or cultural practices involving animal slaughter. Obtaining a history of animal exposures from patients with lesions suspicious for orf and secondary skin eruptions can guide diagnosis and identification of the inciting immune stimulus. Determining the pathophysiology and relative contribution of host and viral factors contributing to EM and other orf-associated hypersensitivity reactions could facilitate the identification of risk factors and inform treatment decisions.

Key words: Immunology, orf, zoonoses.

\section{INTRODUCTION}

Orf is a zoonotic parapoxvirus that is transmitted to humans from sheep and goats. The virus is endemic in sheep and goats worldwide and manifests as an acute contagious skin condition that can cause substantial morbidity [1]. Among humans, orf is typically a mild, self-limiting infection characterized by one or

\footnotetext{
* Author for correspondence: Dr R. H. Joseph, Centers for Disease Control and Prevention, 4770 Buford Hwy NE, Mailstop F-76, Atlanta, GA 30341, USA.

(Email: rjoseph@cdc.gov)
}

multiple lesions on the hand(s) or finger(s) [2]. Infection occurs through inoculation of broken or abraded skin with virus from infectious animal lesions or contaminated fomites [1, 2]. About 3-7 days after inoculation, an orf lesion appears as a papule that slowly progresses to a weeping target lesion that ulcerates and forms a dry crust. No specific treatment is warranted, and lesions resolve within 4-8 weeks $[2,3]$. Although re-infection is possible [4], no personto-person spread occurs under natural conditions [2].

About $30 \%$ of sheep workers in the UK report having had an orf infection [4]; among abattoir workers in New Zealand, mutton slaughtermen have an annual

The online version of this article is published within an Open Access environment subject to the conditions of the Creative Commons Attribution licence <http: //creativecommons.org/licenses/by/3.0/>. The written permission of Cambridge University Press must be obtained for commercial re-use. Parts of this are a work of the U.S. Government and not subject to copyright protection in the United States. 
orf incidence of $\leqslant 4 \%$ [5]. Human orf infections in North America are considered rare [6]. Orf is underrecognized, owing to patient failure to seek care $[4,7]$ and physicians' unfamiliarity with the disease in areas where it is uncommon $[3,6]$. Orf lesions can resemble other localized poxvirus infections, including pseudocowpox and bovine papular stomatitis, as well as more serious conditions (e.g. anthrax, tularemia, primary inoculation tuberculosis, syphilitic chancre, sporotrichosis, pyogenic granuloma, neoplasia) [2].

Complications of orf infection have been reported, including secondary bacterial infection, lymphadenopathy, lymphangitis, giant or recurring lesions, and erythema multiforme (EM) [2]. EM is thought to be a cell-mediated (delayed type) hypersensitivity reaction that can occur after exposure to certain infections and less commonly to drugs [8]. This report describes two cases of EM after orf infection and reviews literature pertaining to orf-associated hypersensitivity reactions.

\section{Case 1}

A previously healthy woman aged 30 years, a veterinarian working at a rural practice in Montana, contacted the Centers for Disease Control and Prevention (CDC) to report two confluent 4-mm indurated, pustular papules, each with an umbilicated centre, on the left index finger (Fig. 1). The papules had developed $\sim 1$ week after treating an injured lamb. She expressed concern about possible orf virus infection, although the lamb (aside from injury) and other sheep had appeared healthy. The patient also reported having sought care for the lesion and swollen axillary lymph nodes at an outpatient clinic, where she was prescribed an oral antibiotic, sulfamethoxazoletrimethoprim. After contacting CDC, she sought care at another outpatient clinic where swabs of the lesion were taken for poxvirus testing; orf virus DNA was detected by polymerase chain reaction (PCR) at the CDC Poxvirus Laboratory.

One week later ( $\sim 2$ weeks after onset of the primary lesion), the patient sought care at an emergency department for a painful rash on the hands, arms, and legs. The medical provider observed multiple vesicular papules on the patient's extremities (Fig. 2). An oedematous ulcer was also noted on her left index finger. The patient was treated with doxycycline pending results of rickettsial disease testing, an antihistamine, and oral and topical corticosteroids. The previously prescribed antibiotics were discontinued.

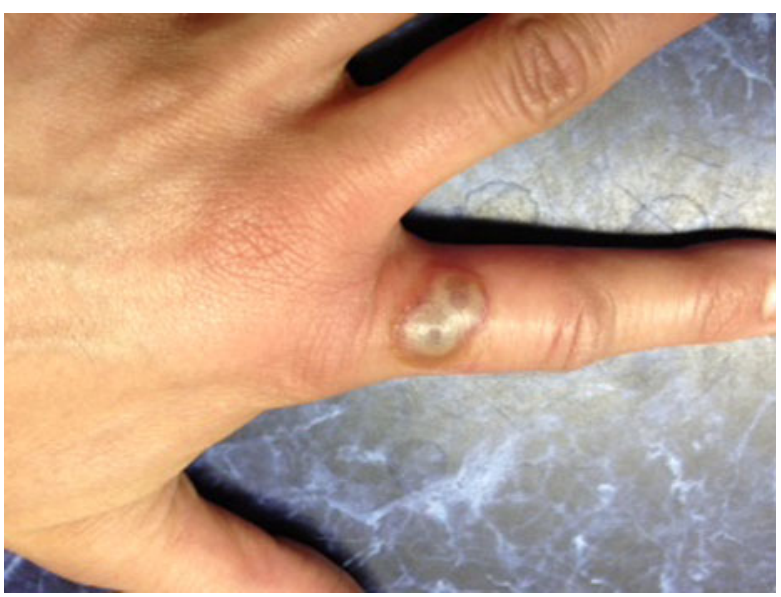

Fig. 1 [colour online]. Primary lesion on the left index finger. Orf virus DNA was detected in a dry swab of this lesion.

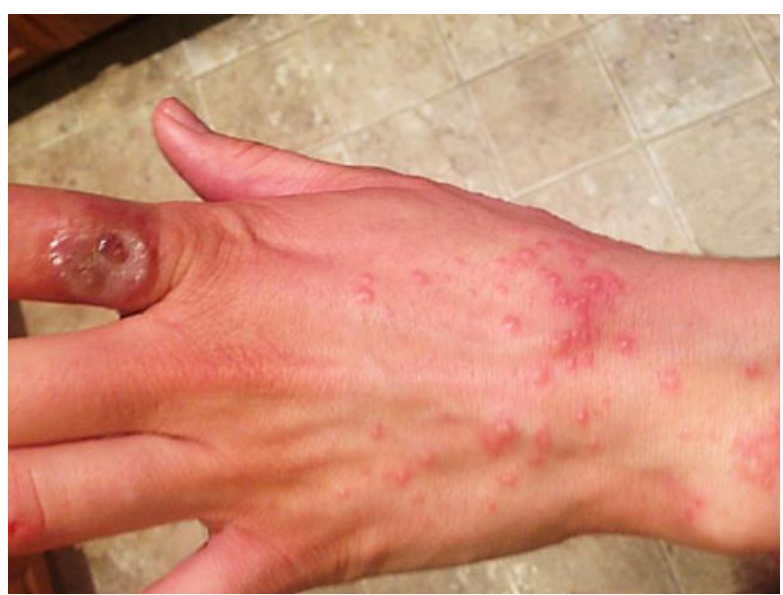

Fig. 2 [colour online]. Vesicular eruption observed $\sim 2$ weeks after onset of primary orf lesion.

Punch biopsy of the primary lesion demonstrated full-thickness epidermal necrosis with evidence of reticular degeneration. Limited eosinophilic cytoplasmic inclusions were identified within the intact epidermis, consistent with aggregations of parapoxvirus particles. Biopsy of the vesicular rash revealed interface dermatitis with an eosinophil-rich inflammatory infiltrate, consistent with EM or drug reaction. The patient took medical leave from work after continuing to develop coalescing targetoid lesions for multiple days after the previous clinic visit (Fig. 3). The patient did not return for a follow-up evaluation.

\section{Case 2}

A man aged 38 years with a medical history of peptic ulcers presented to the emergency department of an 


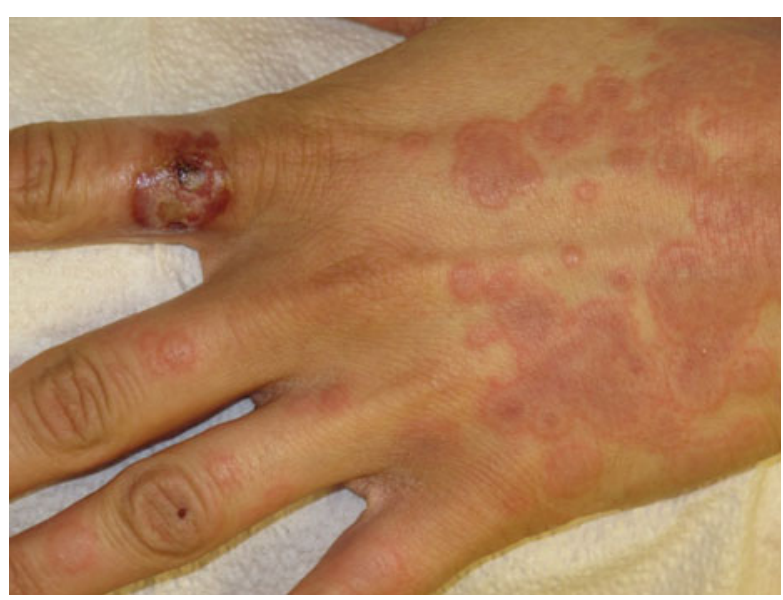

Fig. 3 [colour online]. Coallescing targetoid lesions observed $\sim 3$ weeks after onset of primary orf lesion.

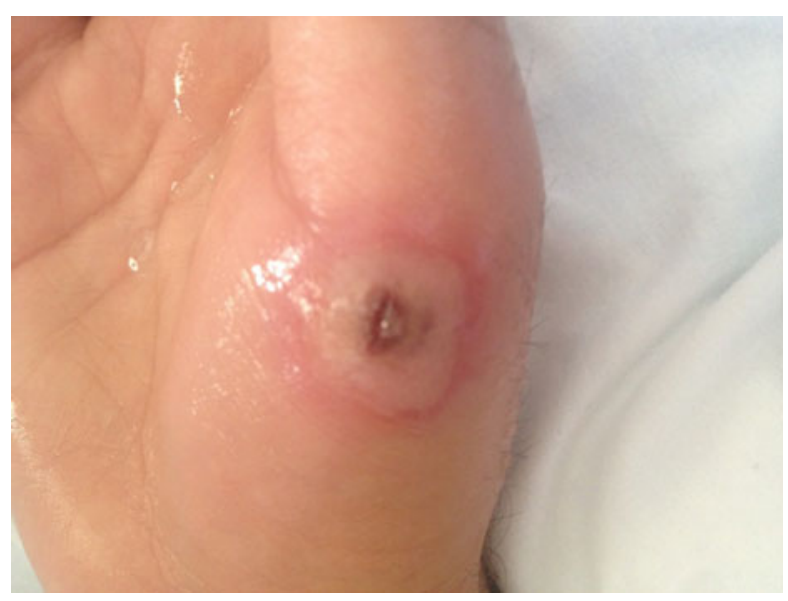

Fig. 4 [colour online]. Blister on right thumb. Orf virus DNA was detected in a dry swab and roof sample of this lesion.

urban community teaching hospital in San Diego, California, with a 6-day history of right hand pain and a blister on the right thumb. During physical examination, a singular, 10-mm-diameter vesicle with a central punctum on the proximal aspect of the right thumb (Fig. 4) that discharged clear fluid was noted. The right hand was tender and swollen with lymphangitis noted on the right forearm. The patient denied fever, chills, or respiratory symptoms; the remainder of the physical examination was unremarkable. When asked about contact with livestock, the patient reported having cut his right thumb while slaughtering a lamb for a religious holiday 3 weeks before; he did not recall the animal having any skin lesions. A clinical diagnosis of orf was made on the basis of lesion appearance and recent history of exposure to a

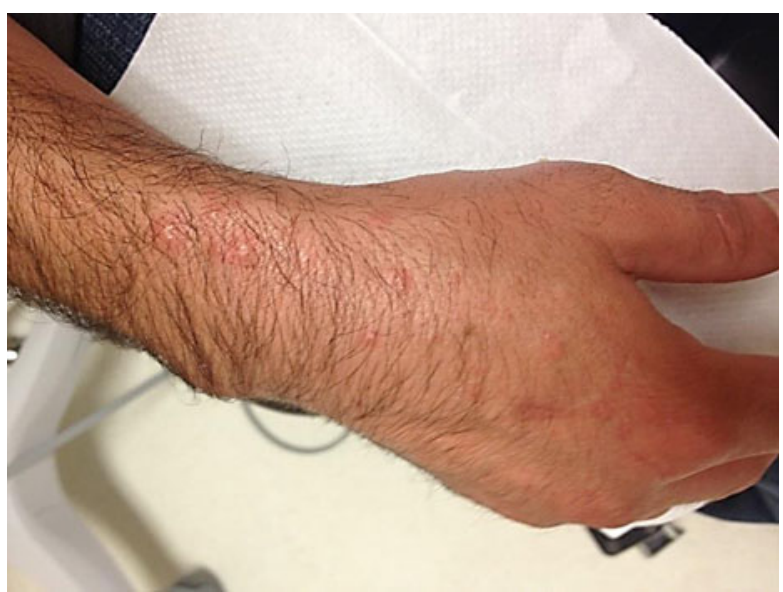

Fig. 5 [colour online]. Maculopapular rash observed 2 weeks after onset of the primary orf lesion.

lamb. The patient was treated with amoxicillin for suspected secondary bacterial infection and discharged for outpatient follow-up.

One week later, the patient returned to the emergency department complaining of a pruritic rash. During physical examination, maculopapular lesions widely dispersed on the patient's hands, palms, and forearms (Fig. 5) were noted. He denied other symptoms, and no other lesions were noted. Dry swabs and a sample of the lesion roof were collected from the primary lesion for orf virus testing. A punch biopsy of a secondary lesion was submitted for histopathology. Oral antibiotics were discontinued, and the patient was treated with antihistamines. The CDC Poxvirus Laboratory confirmed orf virus infection by PCR. Histopathological evaluation of the vesicular rash was indicative of EM or allergic reaction. The patient's rash resolved after 10 days, and the orf lesion healed without further complication.

\section{DISCUSSION}

The patients described in this report each had characteristic orf lesions on the hand and subsequently experienced a hypersensitivity reaction. Orf infection was confirmed by PCR, and a clinical diagnosis of EM was supported by histopathology. Both reported having had recent contact with sheep; however, neither patient recalled seeing skin lesions on the animal. This might have been the case if the lambs were contaminated with infectious material from other animals (orf virus can survive for years in scabs [1]) or had had infectious lesions that were small or nearly healed. 
Within the poxvirus family, secondary immunological reactions (e.g. EM) are most frequently reported in association with orf [9]. A search of the scientific literature using the terms orf or contagious pustular dermatitis and erythema multiforme or hypersensitivity found 10 case reports [10-18] and about 30 instances of EM identified in epidemiological [4, 19-21] and immunological [22] studies of human orf infections. Among patients receiving a diagnosis of orf, an estimated 7-18\% experience EM [19-21].

Orf-associated EM typically develops 2-4 weeks after onset of the primary orf lesion and is characterized by acute onset of symmetrically distributed papules, macules, bullae, and target lesions [11, 13, $14,18]$. Lesions can localize to the hands and forearms $[12,22]$ or more commonly involve the hands and forearms, as well as areas remote from the orf infection, including the feet, legs, neck, and face $[10,11$, $13,14,16-18,20,23]$; the mouth [20] and conjunctiva [17] are less commonly affected. Severity of EM varies; however, the skin eruption is typically self-limiting and resolves from 1 to several weeks.

In other reports, patients with orf-associated EM were treated with various combinations of topical and oral corticosteroids, antihistamines, and antibiotics [10-13, 15-17, 20, 23]. In two patients with EM who failed to respond to corticosteroid and antihistamine treatment, the primary orf lesion and EM rapidly resolved after topical treatment of the orf lesion with the immunomodulatory drug imiquimod [16].

In addition to EM, at least six cases of widespread papulovesicular eruption [4, 20, 24], one case of Stevens-Johnson syndrome [22], and multiple cases of antibody-mediated hypersensitivity reactions have been reported after orf infection. Antibody-mediated reactions included one case of mucus membrane pemphigoid [14], six cases of bullous pemphigoid [25, 26], and two cases of a novel autoimmune bullous disease [27]. Compared to patients with orf-associated EM, patients described in these reports tended to have more severe disease and in certain cases required prolonged treatment with multiple immunosuppressive drugs $[22,25,27]$.

In the two cases presented, antibiotics were discontinued after the secondary skin eruption developed. The role of antibiotics in orf-associated EM is unclear. Often, when patients seek medical care for their infections, antibiotic treatment is prescribed empirically owing to suspicion of primary or secondary bacterial infection. An infectious agent, most commonly herpes simplex virus or Mycoplasma pneumoniae, is the precipitating factor in the majority of EM cases [28]. Drug-associated reactions are suspected to cause $<10 \%$ of EM [28]. Numerous instances in the literature of orf-associated EM in patients with $[15,20]$ and without $[10,11,13,16,20,29]$ known prior treatment with antibiotics have been reported. This indicates that although certain EM eruptions might be wholly or in part because of a drug-associated reaction or a synergistic effect of concurrent drug and virus exposure, a considerable number of eruptions are likely attributable primarily to an immune stimulus emanating from the orf virus. Further epidemiological and immunological studies could help to determine whether antibiotics play a role in the development of orf-associated EM.

The mechanism of orf virus induction of EM is not well understood. The virus produces multiple immunomodulatory virulence factors, which interfere with the host's inflammatory and immune response [1]. Among these is a homologue of mammalian vascular endothelial growth factor, the human form of which has been demonstrated to be substantially upregulated in lesional epidermis of bullous pemphigoid and EM [30]. In one case of orf-induced pemphigoid, autoantibodies to the basement membrane protein, laminin-322, were identified. Possible mechanisms of orf-induced pemphigoid include virus mimicry of host proteins and alteration of basement membrane proteins by the virus [26]. Other viral infections can also trigger hypersensitivity reactions, among the best-studied of which is herpes simplex-associated erythema multiforme (HAEM). HAEM is thought to stem from autoreactive $T$ cells triggered by either viral mimicry of host proteins or release of viral proteins from cells containing viral DNA fragments [8].

The range of host responses to virus infection is diverse, and polymorphisms in genes encoding key immunostimulatory proteins of the orf virus might also play a role in influencing complex outcomes secondary to orf infection [1]. Determining the molecular mechanism(s), pathophysiology and relative contribution of host and viral factors, and possibly drugs, contributing to EM and other orf-associated hypersensitivity reactions will be important because this has bearing on identification of risk factors, clinical treatment decisions, and outcomes.

\section{CONCLUSION}

The cases presented illustrate a relatively common complication of an uncommon although possibly 
under-recognized infection. Although EM is typically mild and self-limiting, it can interfere with work [4] and other activities, result in visits to the emergency department, and in certain cases, hospitalization $[12,15,20]$. Because orf resembles other types of infections and hypersensitivity reactions can be caused by different aetiological agents, obtaining a history of recent animal exposures from patients with lesions suspicious for orf and secondary skin eruptions can potentially guide diagnosis and identification of the inciting immune stimulus.

This report also illustrates the occurrence of orf and its complications in both rural and urban contexts. Awareness of occupational exposures to orf can be high in rural areas [4, 21]. However, opportunities for exposure in urban settings and areas where orf is less well-known can occur among communities with religious or cultural practices involving animal slaughter [6], as well as areas where hobby farming and home butchering are increasingly popular [3]. Physicians should be aware of orf and the array of hypersensitivity reactions it can cause. Further study of underlying virus and host factors, and the possible role of antibiotics in orf-associated EM, might help to identify important virus virulence factors and risk factors for hypersensitivity reactions in humans.

\section{ACKNOWLEDGEMENTS}

The authors acknowledge M. Jones from the Billings Clinic and J. Brodhead from the Richland County Health Department for their clinical consultations. We appreciate the assistance of C. Ballew, S. Helgersen, and K. Milhon from the Montana Department of Public Health and Human Services as well as contributions from D. Molden of the Department of Pathology and L. Evans of the Microbiology Laboratory at Sharp Grossmont Hospital. We also thank H. Zhao, Y. Li, and W. Davidson of the CDC Poxvirus Laboratory for providing laboratory confirmation of clinical samples. This research received no specific grant from any funding agency, commercial or not-forprofit sectors.

The findings and conclusions in this report are those of the authors and do not necessarily represent the official position of the Centers for Disease Control and Prevention.

\section{DECLARATION OF INTEREST}

None.

\section{REFERENCES}

1. Haig DM, et al. Orf virus immuno-modulation and the host immune response. Veterinary Immunology and Immunopathology 2002; 87: 395-399.

2. Diven DG. An overview of poxviruses. Journal of the American Academy of Dermatology 2001; 4: 1-14.

3. Centers for Disease Control and Prevention. Human orf virus infection from household exposures-United States, 2009-2011. Morbidity and Mortality Weekly Report 2012; 61: 245-248.

4. Buchan J. Characteristics of orf in a farming community in mid-Wales. British Medical Journal 1996; 313: 203-204.

5. Robinson AJ, Peterson GV. Orf virus infection of workers in the meat industry. New Zealand Medical Journal 1983; 96: 81-83.

6. Uzel M, et al. A viral infection of the hand commonly seen after the feast of sacrifice: human orf (orf of the hand). Epidemiology and Infection 2005; 133: 653-657.

7. Haig DM, et al. The immune and inflammatory response to orf virus. Comparative Immunology, Microbiology and Infectious Diseases 1997; 20: 197-204.

8. Aurelian L, Ono F, Burnett J. Herpes simplex virus (HSV)-associated erythema multiforme (HAEM): a viral disease with an autoimmune component. Dermatology Online Journal 2003; 9(1)(http://escholarship. org/uc/item/7v35w30d).

9. Ilkit M, Durdu M, Karakas M. Cutaneous id reactions: a comprehensive review of clinical manifestations, epidemiology, etiology and management. Critical Reviews in Microbiology 2012; 38: 191-202.

10. Agger WA, Webster SB. Human orf infection complicated by erythema multiforme. Cutis 1983; 31: 334-338.

11. Azizzadeh M. Case report of orf followed by erythema multiforme. Journal of Semnan University of Medical Sciences 2007; 9: 1-2.

12. Blakemore F, Abdussalam M, Goldsmith WN. A case of orf (contagious pustular dermatitis): identification of the virus. British Journal of Dermatology and Syphilis 1948; 60: 404-409.

13. Coskun O, et al. Human orf complicated with erythema multiforme. International Journal of Dermatology 2008; 47: $1333-1334$.

14. Kahn D, Hutchinson EA. Generalized bullous orf. International Journal of Dermatology 1980; 19: 340 341.

15. de Wet C, Murie J. Lamb pays lip service: two cases of echthyma contagiousum (orf). Scottish Medical Journal 2011; 56: 1-4.

16. Erbağci Z, Erbağci I, Tuncel A. Rapid improvement of human orf (ecthyma contagiosum) with topical imiquimod cream: report of four complicated cases. Journal of Dermatological Treatment 2005; 16: 353-356. 
17. Schmidt E, et al. Orf followed by erythema multiforme. Journal of the European Academy of Dermatology and Venereology 2006; 20: 612-613.

18. Lieu TJ, et al. A generalized eruption in a rancher. Clinical Infectious Diseases 2013; 56: 1675-1676.

19. Ghislain PD, Dinet Y, Delescluse J. Orf in urban surroundings and religious practices: a study over a 3-year period. Annals of Dermatology and Venereology 2001; 128: 889-892.

20. Bassioukas K, et al. Orf clinical and epidemiological study. Australasian Journal of Dermatology 1995; 34: 119-123.

21. Johannessen JV, et al. Human orf. Journal of Cutaneous Pathology 1975; 2: 265-283.

22. Yirrell DL, Vestey JP, Norval M. Immune responses of patients to orf virus infection. British Journal of Dermatology 1994; 130: 438-443.

23. Ferrando MF, et al. Orf and erythema multiforme in a child. Pediatric Dermatology 1997; 14: 154-155.

24. Wilkinson JD. Orf: a family with unusual complications. British Journal of Dermatology 1977; 97: $447-450$.
25. Murphy JK, Ralfs IG. Bullous pemphigoid complicating human orf. British Journal of Dermatology 1996; 134: 929-930.

26. White KP, et al. Orf-induced immunobullous disease: a distinct autoimmune blistering disorder. Journal of the American Academy of Dermatology 2008; 58: 49-55.

27. Thappa DM. Erythema multiforme, Stevens-Johnson syndrome and toxic epidermal necrolysis. In: Bolognia JL, Jorizzo JL, Schaffer JV, eds. Dermatology, 2nd edn. Philadelphia: Saunders, 2008, pp. 288-293.

28. Léauté-Labrèze C, et al. Diagnosis, classification, and management of erythema multiforme and StevensJohnson Syndrome. Archives of Disease in Childhood 2000; 83: 347-352.

29. Brown LF, et al. Increased expression of vascular permeability factor (vascular endothelial growth factor) in bullous pemphigoid, dermatitis herpetetiformis and erythema multiforme. Journal of Investigative Dermatology 1995; 104: 744-749.

30. Van de Bos RR, et al. Orf-induced pemphigoid with antilaminin-332 antibodies. British Journal of Dermatology 2012; 167: 937-963. 